\title{
EFL learners' experience of a MALL-based vocabulary learning tool
}

\author{
Abdullah Alhadiah \\ Department of English Language and Translation, Qassim University, Buraydah 51452, Saudi Arabia.
}

\begin{abstract}
Since vocabulary learning plays a crucial role in the journey of language learning, various programs and mobile applications have been developed to assist vocabulary learning. However, the effectiveness of MALL-based (mobile-assisted language learning) tools can be determined by examining the perception of users, who are learners in this case, because, as Beres (2011) emphasized, learners do not always perceive learning tool effectiveness in the same way as educators. Thus, the primary purpose of this study is to investigate the perspectives of learners regarding the use of one of the programs that can be used for vocabulary learning - Quizlet. The perceptions of thirty-eight Saudi EFL (English as a Foreign Language) freshmen college students regarding the use of Quizlet for fourteen weeks were examined using questionnaires and interviews. The main findings of the study show that the students demonstrated positive attitudes towards the use of Quizlet in English vocabulary learning. They perceived it as a useful program that was easy to use, and they reported the intention to use it in the future. The present study highly recommends the use of MALL-based tools for vocabulary learning for their usefulness inside and outside the classroom.
\end{abstract}

Keywords: EFL; MALL; Vocabulary learning; Quizlet

\begin{tabular}{|ccc|}
\hline \hline $\begin{array}{c}\text { First Received: } \\
\text { 11 May 2020 }\end{array}$ & Revised: & Accepted: \\
Final Proof Received: & 4 September 2020 & 12 September 2020 \\
29 September 2020 & & Published: \\
\hline \hline $\begin{array}{l}\text { How to cite (in APA style): } \\
\text { Alhadiah, A. (2020). EFL learners' experience of a MALL-based vocabulary learning tool. } \\
\text { Indonesian Journal of Applied Linguistics, 10(2), 283-291. } \\
\text { https://doi.org/10.17509/ijal.v10i2.28590 }\end{array}$ \\
\hline
\end{tabular}

\section{INTRODUCTION}

Smartphones have become increasingly ubiquitous in daily life, as they can now offer additional functionality to that predicted initially. One example of the vast rise in the use of smartphones is their application in different educational settings. According to Leis et al. (2015), the growing availability of smartphones and computers since the 1960s has greatly influenced learning. Language learning is one of the learning areas influenced by technology. They also claimed that the increasing availability of smartphones had established them as a tool for learning and teaching in general, and language learning and teaching in particular.

The growing use of smartphones or mobiles in learning has been reflected in research conducted in the field of language education (e.g. Çakmak \&
Erçetin, 2017; Gitsaki \& Robby, 2014; Stockwell \& Hubbard, 2013). Various MALL-based programs are available for teaching and learning different languages (Godwin-Jones, 2011; Heil et al., 2016; Stanley, 2013). In the current study, the discussion focuses mostly on the use of smartphones in vocabulary learning and teaching.

Using smartphones or mobiles in vocabulary learning is an area that has received significant attention from researchers over the last decade, as a variety of applications and programs for language learning, and vocabulary learning, in particular, have been developed for use with the technology (Godwin-Jones, 2011; Heil et al., 2016; Stanley, 2013). Most MALL studies have advocated for the use of mobiles in vocabulary learning and teaching because it has been found to be an effective tool that 
can improve vocabulary learning. For example, Saeidi and Mozaheb (2012) compared the use of a MALL-based vocabulary learning program and the use of traditional paper flashcards by eighty students over seven weeks. Half of the participants were put in the experimental group where they were asked to use their mobiles to study a vocabulary list, whereas the participants in the other group were asked to use paper flashcards to study the same list of the words. The participants from both groups had to take a multiple-choice vocabulary test, and ten participants from each groups were interviewed about their experience. Since the results showed that the experimental group significantly outperformed the control group in the test, Saeidi and Mozaheb (2012) claimed that using MALL in vocabulary learning is more effective than traditional flashcards.

Similarly, Basoglu and Akdemir (2010) compared the use of mobiles in vocabulary learning and the use of traditional paper flashcards among sixty college students, who were put into two groups (experimental and control). In addition to taking a multiple-choice vocabulary test after six weeks of studying new words, all participants had to take a multiple-choice pre-test to examine their vocabulary acquisition. Futhermore, eight students from the experimental group were interviewed. Although both groups demonstrated improvement in vocabulary learning, the experimental group significantly outperformed the control group in the post-test. Furthermore, the qualitative part of the study indicated that using mobiles during the sixweek experiment positively influenced students' perceptions of using mobiles in vocabulary learning. Therefore, the author argued that using mobiles in vocabulary learning is more effective than using traditional flashcards.

Alavinia and Qoitassi (2013) used questionnaires, multiple-choice vocabulary tests, and interviews to examine the attitudes of a group of English learners towards the use of short message service (SMS) in vocabulary learning. The study included forty students, who were divided into control and experimental groups, and lasted for four months. The participants demonstrated positive attitudes towards mobile-based vocabulary learning, and the results indicated that using mobiles in vocabulary learning improved the students' vocabulary.

In sum, these studies demonstrated the effectiveness of using mobiles in vocabulary learning and showed that learners have positive attitudes towards MALL-based vocabulary learning. However, two points must be noted regarding these studies. First, the use of mobiles in Alavinia and Qoitassi's (2013) research was minimal, as they used SMS, which is a MALL-based strategy but cannot be compared with the programs that have been designed specifically for learning purposes and equipped with various learning features. Second, there is a possibility that the results of Saeidi and Mozaheb's (2012) and Basoglu and Akdemir's (2010) studies were influenced by novelty, whereby the study subjects demonstrated enthusiasm during initial exposure to a new use of technology (Chwo et al., 2018; Stockwell \& Hubbard, 2013). Indeed, Clark and Sugrue (1991) argued that the effect of novelty needs at least eight weeks to be decreased to the minimum level.

Due to the availability of new programs and applications that have been tailored to specific purposes, researchers have identified the need to focus on specific programs designed to serve specific learning goals. A program that has been examined in recent years is Quizlet, which is a learning website and mobile application that enables students as well as teachers to learn using a variety of features, including Flashcards, Learn, Write, Spell, Test, Match, and a Live feature which allows collaboration and competition (Quizlet, 2019).

Dizon (2016) administered pre- and post-tests to nine Japanese college students studying academic English vocabulary at a Japanese university to examine the effectiveness of using Quizlet in vocabulary learning over a period of ten weeks. In addition, the students' perceptions were explored via a closed-ended questionnaire. The results of the research showed that Quizlet was effective in vocabulary learning. Furthermore, the participants demonstrated positive attitudes toward the use of the program in vocabulary learning. Similarly, Lander (2016) qualitatively examined the perceptions of 830 Japanese college students who used Quizlet to study English vocabulary over the course of one academic year. The participants had to answer a sixpoint Likert scale question and reflective openended question regarding their opinions about using Quizlet as a vocabulary learning tool. The results indicated that the majority of participants had positive attitudes towards the use of the program.

Furthermore, a study by Lam et al. (2018) explored the attitudes of twenty-three seventh and eighth grade students in the United States regarding the use of Quizlet to learn Chinese. Participants were asked to respond to a five-point Likert scale questionnaire after using Quizlet for one semester. The results revealed mixed findings and showed that the participants were hesitant to use Quizlet at home or every day.

A review of the existing literature indicates that recent research in this area has tended to focus more on learners' acceptance and perceptions of MALL-based programs than the efficacy of such programs. This could be because "our students' conceptions about effective learning strategies may not necessarily match our conceptions about effective instructional design, and we need to explore both" (Beres, 2011, p. 109). Davis (1989) proposed technology acceptance model (TAM) and claimed that perceived usefulness (PU) and 
perceived ease of use (PEOU) could determine user's behavioral intention (BI) and acceptance of a given program. Davis (1989) defined PU as "the degree to which a person believes that using a particular system would enhance his or her job performance" (p. 320), and PEOU as "the degree to which a person believes that using a particular system would be free of effort" (p. 320).

In addition, in the brief literature review presented above, studies that have investigated the use of Quizlet in vocabulary learning have been purely qualitative in nature (Lander, 2016), purely quantitative and conducted with young learners (twelve to fourteen years old; Lam et al., 2018), or informed by a relatively small-sized population (Dizon, 2016). Therefore, they have generally lacked the triangulation of methods that could provide more information about the participants and increase the validity and reliability of the findings. According to Marek and Wu (2014, p. 564), "language learning is a complex dynamic system in which multiple and changing internal and external factors, which can be difficult or impossible to control, affect EFL learning outcomes and that these should be taken into account in CALL instructional design." Therefore, in an attempt to fill the observed gap in the literature, the current study adopted a mixed-method research design that employed both quantitative and qualitative methods to investigate EFL learners' perceptions of using Quizlet in vocabulary learning over a period of fourteen weeks. Due to the differences in learners' perceptions reported in the literature (e.g., Chien, 2013; Lam et al., 2018; Lander, 2016) and due to the scarcity of studies examining the use of Quizlet in the context of EFL in Saudi Arabia, where English is a foreign language, this study sought to shed some light on the attitudes of Saudi students to Quizlet as a tool of vocabulary learning. This study was mainly designed to answer the following research questions:

1. What were students' preferences regarding the use of Quizlet in English vocabulary learning?

2. How often did students use Quizlet in English vocabulary learning outside the classroom?

3. What were students' attitudes towards the use of Quizlet in English vocabulary learning?

\section{METHOD}

\section{Research design}

In an attempt to answer the research questions comprehensively, this research used a mixedmethod design, which allows for both qualitative and quantitative data to be collected in a single study. Data for the study was obtained from an online questionnaire and semi-structured interviews.
According to Creswell (2014, p. 215), "This mixing or blending of data, it can be argued, provides a stronger understanding of the problem or question than either by itself."

\section{Settings and participants}

The study took place in a mandatory preparatory year program (PYP) in a Saudi public university. A PYP is a two-semester course, and its primary goal is to improve students' English language skills so they can pursue studies in fields that use English as a medium of instruction, such as engineering, architecture, medicine, dentistry, and pharmacy. The program consists of two general English courses: reading and writing course, and listening and speaking course. It also includes a course in English for specific academic fields. In addition, in order to facilitate the transition from Arabic instruction in high school to English instruction, students are taught some basic science, computer sciences, and mathematics courses in English. The study was conducted in this context because it represented a very common phenomenon of learning English in Saudi Arabia EFL context (McMullen, 2014).

The participants of this study were thirty-eight male first-year students enrolled in the listening and speaking PYP class. Their first language was Arabic, and their ages ranged between eighteen and twenty-two years old. The class met twice a week for two hours each time. The study was conducted in Fall 2019 over a period of fourteen weeks, which was long enough to decrease the effect of novelty (Chwo et al., 2018; Clark \& Sugrue, 1991). The researcher chose this population of EFL students because they were young adults who were technology native and had the desire to improve their English to pursue their education in Englishspeaking colleges. In addition, all of them had their own smartphones and had access to a fast Internet connection; therefore, the affordance and access were considered while designing the study and selecting the population, as advised in Chwo et al. (2018). In other words, they needed to learn English, and they had all of the necessary equipment to use MALL-based tools.

\section{Procedure}

Quizlet was introduced to the participants in the first week, and the students were shown how the program worked and how they could use it in their English vocabulary learning. The instructor explained in detail where to find the program, how to download it, how to create an account, how to search for study sets, how to use study sets, how to create study sets, how to find study classes, and how to join study classes and groups. During the first week, the instructor asked the students to download the application on their mobiles and join the online class in Quizlet, which contained study sets related to the lessons. These sets were used in the lessons 
both collaboratively and individually during the first two weeks in order to increase students' familiarity with Quizlet and to cover the vocabulary in the first unit the textbook (Unlock Listening and Speaking Skills, level 3).

In the second week, students were asked to start creating their own study sets on their Quizlet pages by adding a minimum of twenty words from the PYP courses they were taking that semester. To let them explore the program, they were allowed to design their own sets, and there was no specific design or format they needed to follow. They were also asked to share their sets on the class Quizlet page, and they were encouraged to look at their classmates' sets.

Quizlet was used in almost all of the class meetings throughout the semester, and the students were encouraged to use it inside and outside the classroom. The instructor employed various Quizlet features in the class, including Flashcards, Learn, Write, Spelling, Test, Match, and Live.

After fourteen weeks, a survey questionnaire regarding students' experience of using Quizlet was administered in the class, and the participants were asked to complete it voluntarily. The instructor also asked for volunteers to participate in short interviews about their experience of using Quizlet. Eight students volunteered to participate in the interviews, which were conducted and recorded by the instructor in his office.

\section{Instruments}

The data for this study were obtained from two data collection instruments: a questionnaire and a semistructured interview. The questionnaire was adapted from Dizon (2016) and slightly modified. The original questionnaire (Dizon, 2016) included 12 items, and they were as follows: one item about whether participants preferred using Quizlet via computer or smartphone; one item about the amount of time they spent on Quizlet outside the classroom; ten Likert-scale items ranging from "strongly agree" to "strongly disagree" (indicated by 1 to 5 , respectively) to examine the participants' attitudes toward Quizlet.

The researcher made two changes to the original questionnaire. First, the second item of the original questionnaire asked about the time students spent studying vocabulary with Quizlet outside the classroom and gave four choices, of which "less than twenty minutes each week" was the least amount of time that could be chosen. However, to ascertain if the students did not give Quizlet any time, this item was modified in the present study, and one more choice was added: "I did not give it any time in my week". Second, one more item was added to elicit students' preferences regarding the program features, such as Flashcards, Spell, and Live. Since Dizon (2016) created the questionnaire based on Davis's (1989) TAM, he classified the ten
Likert-scale items into three constructs: PU (4 items), PEOU (4 items), and BI (2 items).

With the help of two applied linguistics professors, the questionnaire was translated into the participants' first language (L1, Arabic) to facilatate the students' understanding of the questionnaire items.

In an attempt to obtain more detailed responses from the participants, the researcher designed a semi-structured interview reflecting the concepts surveyed in the questionnaire. The interviews were designed to last approximately fifteen to twenty minutes each. The language used in the interviews was Arabic because it was easier for the participants to express their ideas in their L1. The interviews were tape-recorded after informed consent had been obtained.

\section{Data analysis}

Since this study employed a convergent parallel mixed-methods design (Creswell, 2014), the researcher collected qualitative and quantitative data concurrently, analyzed them separately, and, finally, combined the results to obtain more rigorous answers to the research questions. Statistical Package for Social Science (SPSS) software was used to analyze the quantitative data. Descriptive analysis was calculated, as well as Pearson's correlation with specific items. The tape-recorded interviews were transcribed and qualitatively analyzed using two stages of coding, as explained by Dörnyei (2007), in an attempt to complement the quantitative results of the questionnaire.

\section{RESULTS}

Because this study was a mixed-method study, the quantitative results are presented in this section alongside the qualitative data to allow elaboration on the statistical findings and to provide comprehensive answers to the research questions.

\section{Students' preferences regarding the use of Quizlet}

The first research question is related to the students' preferences regarding the use of Quizlet in English vocabulary learning. To answer this question, the participants were asked in the questionnaire to report whether they preferred using computers or smartphones to study vocabulary in Quizlet, as stated in the first and third items in the questionnaire. They were also given a list of Quizlet features and asked to choose the features they preferred.

According to the participants' responses to the first item in the questionnaire, all of the participants preferred studying English vocabulary in Quizlet using their smartphones rather than computers. When asked in the interviews about their preference for using smartphones rather than computers, they 
emphasized the smartphones' ubiquity, portability, availability, and ease of use as the reasons behind their choices. For example:

Student F: "I prefer using Quizlet in my phone because it is faster and available all the time. I have my phone all day long. I would not open my PC to use Quizlet. I don't want to sit in a specific place to use Quizlet."

Student C: "I prefer using a mobile application because the mobile is portable. Actually, I have not tried it on PC because I don't have a personal PC or laptop, but I have a personal mobile. I don't need a PC. I do most of my work on my mobile."

Student E: "The mobile is fast and easy to use, and you can use it anywhere. It is easy just to start using it."

The third item in the questionnaire asked the participants to choose the Quizlet features they preferred the most (Learn, Flashcards, Write, Match, Test, and Live). It is important to note that no specific feature was highlighted when Quizlet was first introduced, nor were students forced to use a specific feature. As shown in Table 1, the students' preferences were distributed relatively evenly among these six features, with the feature Learn being the most preferred (34\%) and the feature Test being the least preferred $(5 \%)$.

Table 1

Students' Preferred Quizlet Features

\begin{tabular}{lcr}
\cline { 1 - 2 } _Frequency & Percent & \\
\hline Learn & 13 & 34.2 \\
Flashcards & 8 & 21.1 \\
Write & 4 & 10.5 \\
Match & 4 & 10.5 \\
Test & 2 & 5.3 \\
Live & 7 & 18.4 \\
Total & 38 & 100.0 \\
\hline
\end{tabular}

The questionnaire did not elicit the reasons for their feature preferences; however, the interviews revealed that preference was related to the students' goals of using the application, their needs, their priorities, and their personalities. For example:

\begin{abstract}
Student A: "The feature I like the most is Match because it can examine my understanding of meaning. If you don't know the meaning, it very hard to have the correct match. Therefore, I found it beneficial, especially because it is a timed task and requires a high level of concentration."
\end{abstract}

Student B: "I don't use Flashcards because I think it is not beneficial for me. I usually use Match and Write because they really can improve my spelling."

Student F: "I use Learn in class. I also found Live unique to Quizlet... something that would not be available in other programs."

Frequency of using Quizlet outside the classroom To provide the answer to the second research question, the participants were asked in the second item of the questionnaire to report the amount of time they gave to Quizlet outside the classroom in the questionnaire. As shown in Table 2, the majority $(57.9 \%)$ of the participants gave Quizlet some time but less than twenty minutes a week. Nine participants reported that they did not give Quizlet any time outside the classroom, and six participants reported giving Quizlet between twenty to forty minutes a week. Only one student reported spending more than an hour every week on Quizlet. The interviews revealed that most of the students believed Quizlet to be beneficial, but they tended not to use it very often because they were very busy with their PYP courses, which took up most of their time. Some of the participants considered using Quizlet in the future when they had finished their PYP and had more time, such as during the summer break.

Table 2

Amount of Time Students Spent on Quizlet Outside the Classroom

\begin{tabular}{crr} 
_Frequency & Percent & \\
\cline { 1 - 2 } I did not give it any time in my week. & 9 & 23.7 \\
Less than twenty minutes each week. & 22 & 57.9 \\
Between twenty to forty minutes each week. & 6 & 15.8 \\
More than sixty minutes each week. & 1 & 2.6 \\
Total & 38 & 100.0 \\
\hline
\end{tabular}

\section{Students' attitudes towards Quizlet}

To provide the answer to the third research question, the last ten items in the questionnaire were analyzed. The descriptive statistics are reported in this section. The Cronbach's alpha of this part of the questionnaire was $\alpha=0.84$, indicating a high level of internal consistency of the questionnaire items. The descriptive statistics (means and standard deviations) of the three constructs (PU, PEOU, and BI) are presented in Table 3, which shows that the students demonstrated overall positive attitudes towards Quizlet. The highest levels of agreement occurred for PU $(M=4.18, S D=.64)$ and PEOU $(M$ $=4.12, S D=.68)$. Although the mean for BI was not as high as the mean for the first two constructs, it nevertheless indicated a high level of agreement $(M$ $=3.78, S D=.91)$. In sum, the majority of the participants perceived Quizlet as a useful tool for English vocabulary learning that was easy to use. 
They also reported an intention to use it in the

future.

Table 3

Students' Attitudes Towards Quizlet (PU, PEOU, \& BI)

\begin{tabular}{|c|c|c|c|c|c|}
\hline - $\mathbf{N}$ & $\begin{array}{c}\text { Minim } \\
\text { um }\end{array}$ & Maximum & Mean & $\begin{array}{l}\text { Std. } \\
\text { Deviati } \\
\text { on }\end{array}$ & \\
\hline \multicolumn{6}{|l|}{ Perceived Usefulness (PU) } \\
\hline $\begin{array}{l}\text { I was able to learn English vocabulary } \\
\text { more quickly with Quizlet. }\end{array}$ & 38 & 2.00 & 5.00 & 4.16 & .68 \\
\hline $\begin{array}{l}\text { Using Quizlet improved my English } \\
\text { vocabulary. }\end{array}$ & 38 & 2.00 & 5.00 & 4.13 & .74 \\
\hline $\begin{array}{l}\text { Using Quizlet made it easier to learn } \\
\text { English vocabulary. }\end{array}$ & 38 & 1.00 & 5.00 & 4.26 & .86 \\
\hline I think Quizlet was useful in my class. & 38 & 1.00 & 5.00 & 4.16 & 1.08 \\
\hline Total & 38 & 2.25 & 5.00 & 4.18 & .64 \\
\hline \multicolumn{6}{|l|}{ Perceived Ease of Use (PEOU) } \\
\hline $\begin{array}{l}\text { It was easy for me to study English } \\
\text { vocabulary with Quizlet. }\end{array}$ & 38 & 2.00 & 5.00 & 4.18 & .80 \\
\hline $\begin{array}{l}\text { It was easy for me to become skillful at } \\
\text { studying English vocabulary with } \\
\text { Quizlet. }\end{array}$ & 38 & 2.00 & 5.00 & 3.82 & .93 \\
\hline $\begin{array}{l}\text { Learning how to study English } \\
\text { vocabulary with Quizlet was easy for } \\
\text { me. }\end{array}$ & 38 & 2.00 & 5.00 & 4.16 & .89 \\
\hline $\begin{array}{l}\text { The Quizlet website and/or mobile app } \\
\text { was clear and understandable. }\end{array}$ & 38 & 1.00 & 5.00 & 4.32 & .93 \\
\hline Total & 38 & 2.25 & 5.00 & 4.12 & .68 \\
\hline \multicolumn{6}{|l|}{ Behavior Intention $(\mathrm{BI})$} \\
\hline $\begin{array}{l}\text { I intend to study English vocabulary } \\
\text { with Quizlet in the future. }\end{array}$ & 38 & 1.00 & 5.00 & 3.45 & 1.20 \\
\hline $\begin{array}{l}\text { If it is offered, I intend to study English } \\
\text { vocabulary with Quizlet. }\end{array}$ & 38 & 2.00 & 5.00 & 4.11 & .92 \\
\hline Total & 38 & 1.50 & 5.00 & 3.78 & .91 \\
\hline
\end{tabular}

All of the four items in PU received responses with means higher than 4, which indicated a high level of agreement with the statements related to PU. Within the PU construct, the third item received the highest level of agreement $(M=4.26, S D=.86)$ whereas the second item had the lowest $(M=4.13$, $S D=.74)$. The first and fourth item in PU had the same mean value $(M=4.16)$. These results indicated that the participants perceived Quizlet as a useful vocabulary learning tool.

The interviews with the students revealed that they perceived Quizlet as a useful vocabulary learning tool that could support several aspects of vocabulary learning, such as spelling and meaning knowledge. For example:

Student C: "It improved my vocabulary, especially in the ESP course."

Student E: "Quizlet is an effective way of learning vocabulary, if you give it enough time. I think you need to give it at least thirty minutes every day."

Student H: "I found Quizlet useful for writing because it improved my spelling a lot. I would recommend it for everyone who would like to improve his/her spelling in English. Because, as you know, spelling is a challenge."

Student A: "It is very beneficial for two things: spelling improvement and vocabulary meaning. It helped me to have a good vocabulary in different PYP courses."

Student D: "I like the way that Quizlet allows sharing. I shared my study sets with my friends, and I used their sets to learn more and more. I found sharing an effective way of learning vocabulary. Also, I used, sometimes (search) to find specific words or terms related to specific fields. For example, for my biology class, I used (search) and found several sets about biology. I collected some of them and studied them."

Student G: "I used it when studying for midterm exams and some quizzes in several subjects, and it was very useful. I prefer to use Quizlet rather than the books because it is less boring. It is interesting."

Student G: "Using the feature (Live) in class was very competitive, and it encouraged us to study before class to beat other groups. And, as you know, this is a way of learning. It was a combination of fun and learning at the same time."

Student F: "Studying vocabulary from books is boring, whereas using a phone is much more interesting because it is like using a phone for social networking or games applications."

The means of the four items in PEOU ranged from $(M=3.82)$ to $(M=4.32)$. Whereas the fourth item in PEOU had the highest level of agreement ( $M$ 
$=4.32, S D=.93)$, the second one received the lowest $(M=3.82, S D=.93)$. The first and the third items in PEOU had very similar means $(M=4.18$, $S D=.80 ; M=4.16, S D=.89$, respectively). This high level of agreement in PEOU indicated that using Quizlet in vocabulary learning was easy and understandable.

The interviews with the students also showed that they perceived Quizlet as an accessible learning tool they could use to study English vocabulary. For instance:

Student F: "Using Quizlet is easier than opening a book to learn words as in the traditional way of learning vocabulary."

Student G: "The application was super easy, and the design was amazing. I found it a user-friendly application."

Student E: "I highly recommend using Quizlet in vocabulary learning because it is fast, and you can use it anywhere. And it has an app for mobile. You don't have to have a PC to use it. It is easy to sign up and sign in ... etc."

Student A: "The application is straightforward and does not require advanced English language ability. Even if you have basic English, you still can use the program effectively."

Although the first item in BI had a mean of less than $4(M=3.45, S D=1.20)$ which was the lowest mean of the ten items in the questionnaire, the second BI item had a mean of greater than $4(M$ $=4.11, S D=.92)$, which indicated a general tendency towards using Quizlet in the future.

When the students were asked in the interviews about their intention to use Quizlet in the future, the majority of the participants were enthusiastic about future use; however, some identified the condition of finding terminology sets related to their future fields of study. One of the participants claimed that the use of Quizlet presently and in the future depended heavily on learners' passion for learning.

Student A:" I'm planning to use it in summer when I have so much free time."

Student B: "I'll definitely use it in the future when I get to my college. For example, I am going to use it for the definitions of technical terms related to medicine. I think this will allow me to have all of the important definitions in one organized place. So, it is going to be a reference tool."

Student D: "I may not use it in the future unless I find active study groups who share beneficial study sets in the field of pharmacy."

Student F: "Students need to have a goal and a passion for vocabulary learning to consider Quizlet a helpful tool. If they don't have such passion, they will not use it. So, I strongly believe that passion is the driver. Quizlet did not trigger such passion."

In an attempt to examine the extent to which PU and PEOU can influence BI, Pearson's correlations were calculated to show the relationship between these constructs. As shown in Table 4, Pearson's $r$ data analysis revealed a moderated positive correlation between PU and BI and between PEOU and BI ( $r=.57$ and $r=.37$, respectively). Students who perceived Quizlet as a useful and easy to use application reported a greater intention to use Quizlet.

Table 4

Pearson's r for PU, PEOU, and BI

\begin{tabular}{|c|c|c|c|c|}
\hline _Perceived_usefulness & & ved_ease & $\begin{array}{l}\text { Behavioral_intenti } \\
\text { on }\end{array}$ & \\
\hline Perceived_usefulness & $\begin{array}{l}\text { Correlation } \\
\text { Sig. } \\
\text { N }\end{array}$ & $1.000^{* * *}$ & & \\
\hline Perceived_ease & $\begin{array}{l}\text { Correlation } \\
\text { Sig. } \\
\text { N }\end{array}$ & $\begin{array}{r}.593^{* *} \\
.000^{* *} \\
38.000^{* *}\end{array}$ & 1.000 & \\
\hline Behavioral_intention & $\begin{array}{l}\text { Correlation } \\
\text { Sig. } \\
\text { N }\end{array}$ & $\begin{array}{r}.569^{* *} \\
.000^{* *} \\
38.000^{* *}\end{array}$ & $\begin{array}{c}.366^{*} \\
.024^{*} \\
38.000\end{array}$ & 1 \\
\hline
\end{tabular}

**. Correlation is significant at the 0.01 level (2-tailed).

*. Correlation is significant at the 0.05 level (2-tailed).

\section{DISCUSSION AND CONCLUSION}

The main purpose of this study was to investigate the perceptions of Saudi EFL freshmen college students regarding the use of Quizlet to study English vocabulary over a period of fourteen weeks. This type of evaluation is essential because learners' perceptions of MALL do not always match the conceptions of educators (Beres, 2011).

In terms of students' preferences regarding the use of Quizlet, all the participants preferred using the program on their mobiles rather than their PCs because of smartphones' ubiquity, portability, availability, and ease of use. This supports the work 
of Dizon (2016), who found that the majority of the study participants preferred using Quizlet via mobiles, although PCs offered more features and information. However, in Chien's (2013) study, most of the participants did not use Quizlet on mobile because they could not access the Internet using their mobiles. In the current study, all of the participants had access to a fast Internet connection at all times.

Similar to the research conducted by Dizon (2016), most of the participants (76\%) in the current study reported giving Quizlet some time outside the classroom, even when they were not forced to do so, which suggests that they found it a useful tool for vocabulary learning. In terms of students' preferred Quizlet features, different students chose different features for various reasons, which could indicate that Quizlet was effective in providing them with a range of features that can meet their different learning styles and different learning goals.

The quantitative and qualitative results of the study revealed that the students demonstrated positive attitudes towards using Quizlet in vocabulary learning. This is in line with previous studies (e.g., Alavinia \& Qoitassi, 2013; Basoglu \& Akdemir, 2010; Dizon, 2016; Lander, 2016), in which students reported positive attitudes towards Quizlet. In the present study, the vast majority of the participants perceived Quizlet as a useful tool that made it easier and faster to learn and improve their English vocabulary in a way that was interesting, fun, and competitive. They also considered it a userfriendly program that was clear, well-designed, and easy to use for studying vocabulary. Furthermore, some participants emphasized that using Quizlet was much more comfortable and more convenient than using books to learn English vocabulary.

The participants in this study also reported a strong intention to use Quizlet in the future, which contradicts with the findings of Lam et al. (2018), in which students did not consider using Quizlet in the future. This contradiction between the results of the two studies could be attributed to the age of the participants since the participants in Lam et al.'s (2018) study were relatively young (twelve to fourteen years old), whereas the sample of the population in the present study was older (eighteen to twenty-two years old). It seems that learners' age could affect their attitudes toward Quizlet; therefore, Lam et al.'s (2018) claimed that younger learners' reluctance to use Quizlet "is probably because the Quizlet is solely a language learning tool, not a game that students can play for fun" (p.134).

The present study encourages using MALLbased tools for vocabulary learning since they are perceived as useful tools that can be utilized inside and outside the classroom. It is also recommended to select user-friendly MALL-based tools that offer a range of learning features that can meet the different goals and needs of learners.
In conclusion, more research studies investigating students' attitudes toward MALLbased tools are still needed, especially those that consider learners' ages, genders, learning styles, and language proficiency. That is because learners' attitudes are very likely to be influenced by various internal and external factors.

\section{REFERENCES}

Alavinia, P., \& Qoitassi, K. (2013). On the viability of vocabulary learning enhancement through the implementation of MALL: The case of Iranian EFL learners. Journal of Language Teaching \& Research, 4(2). https://doi.org/10.4304/jltr.4.2.412-426

Basoglu, E. B., \& Akdemir, O. (2010). A comparison of undergraduate students' English vocabulary learning: Using mobile phones and flashcards. Turkish Online Journal of Educational Technology, 9(3), 1-7. https://eric.ed.gov/?id=EJ898010

Beres, D. L. (2011). Mobile-assisted language learning from the student perspective: Encouraging effective language learning strategies outside of the classroom. In Academic podcasting and mobile assisted language learning: Applications and outcomes (pp. 93-110). IGI Global.

Çakmak, F., \& Erçetin, G. (2017). Effects of gloss type on text recall and incidental vocabulary learning in mobile-assisted L2 listening. ReCALL, 29(3), 1-24. https://doi.org/10.1017/S0958344017000155

Chien, C. W. (2013). Perception and practice of Taiwanese EFL Learners' making vocabulary flashcards on" Quizlet". Presented at the International Association for Development of the Information Society (IADIS) International Conference on e-Learning, Prague, Czech Republic, 2013.

Chwo, G. S. M., Marek, M. W., \& Wu, W. C. V. (2018). Meta-analysis of MALL research and design. System, 74, 62-72. https://doi.org/10.1016/j.system.2018.02.009

Clark, R. E., \& Sugrue, B. M. (1991). Research on instructional media. In G. Anglin (Ed.), Instructional technology: Past, present, and future (pp. 327-343). Libraries Unlimited.

Creswell, J. W. (2014). Research design: Qualitative, quantitative, and mixed methods approaches. Sage Publications.

Davis, F. D. (1989). Perceived usefulness, perceived ease of use, and user acceptance of information technology. MIS Quarterly, 13(3), 319-340. http://www.jstor.org/stable/249008

Dizon, G. (2016). Quizlet in the EFL classroom: Enhancing academic vocabulary acquisition of Japanese university students. Teaching English with Technology, 16(2), 40-56. 
https://www.ceeol.com/search/articledetail $? \mathrm{id}=408428$

Dörnyei, Z. (2007). Research methods in applied linguistics: Quantitative, qualitative, and mixed methodologies. Oxford University Press.

Gitsaki, C., \& Robby, M. A. (2014). Post-secondary students using the iPad to learn English: An impact study. International Journal of Mobile and Blended Learning, 6(4), 53-74. https://doi.org/10.4018/ijmbl.2014100104

Godwin-Jones, R. (2011). Mobile apps for language learning. Language, Learning and Technology, 15(2), 2-11.

http://llt.msu.edu/issues/june2011/emerging.pd $f$

Heil, C. R., Wu, J. S., Lee, J. J., \& Schmidt, T. (2016). A review of mobile language learning applications: Trends, challenges, and opportunities. The EuroCALL Review, 24(2), 32-50. https://doi.org/10.4995/eurocall.2016.6402

Lam, E. T., Wang, L. C. C., \& Zhao, X. W. (2018). Students' perception of Quizlet as a Chinese learning tool: A preliminary study. International Journal of Technology Enhanced Learning, 10(1-2), 128-136. https://doi.org/10.1504/ijtel.2018.10008601

Lander, B. (2016). Quizlet: what the students think a qualitative data analysis. In S. PapadimaSophocleous, L. Bradley \& S. Thouësny (Eds), CALL communities and culture - short papers from EUROCALL 2016 (pp. 254-259).

Leis, A., Tohei, A., \& Cooke, S. D. (2015). Smartphone assisted language learning and autonomy. International Journal of ComputerAssisted Language Learning and

Teaching, 5(3), 75-88.

https://doi.org/10.4018/ijcallt.2015070105

Marek, M. W., \& Wu, W. C. V. (2014).

Environmental factors affecting computerassisted language learning success: A Complex Dynamic Systems conceptual model. Computer Assisted Language Learning, 27(6), 560-578. https://doi.org/10.1080/09588221.2013.776969

McMullen, M. (2014). The value and attributes of an effective preparatory English program: Perceptions of Saudi university students. English Language Teaching, 7(7), 131-141. https://doi.org/10.5539/elt.v7n7p131

Quizlet. (2019). Retrieved September 19, 2019, https://quizlet.com/en-gb/mission

Saeidi, M., \& Mozaheb, M. A. (2012). Comparing vocabulary learning of EFL learners by using two different strategies (mobile learning vs. flashcards). International Journal of Mobile Learning and Organisation, 6(3-4), 303-315. https://doi.org/10.1504/ijmlo.2012.050050

Stanley, G. (2013). Language learning with technology: Ideas for integrating technology in the classroom. Cambridge University Press.

Stockwell, G., \& Hubbard, P. (2013). Some emerging principles for mobile-assisted language learning. The International Research Foundation for English Language Education, 1-15. 